\title{
The role of brigatinib in crizotinib-resistant non-small cell lung cancer
}

This article was published in the following Dove Press journal: Cancer Management and Research

\section{Laura Mezquita \\ David Planchard}

Medical Oncology Department, Gustave Roussy, Villejuif, France

Correspondence: David Planchard Thoracic Oncology Group, Gustave Roussy, I I4, rue Edouard Vaillant, 94805 Villejuif, France

Tel +330142 II 4564

$\mathrm{Fax}+330142115219$

Email david.planchard@gustaveroussy.fr

\begin{abstract}
Despite the advances in new targeted therapies in ALK positive population, most patients progress under ALK inhibitors within first 2 years; being the brain the most frequent site of relapse. ALK mutations, in $\sim 30 \%$ of patients, are the main known mechanism of resistance. Classically, second-generation ALK inhibitors have been the standard of care in the crizotinibresistant population; however, each ALK inhibitor has a different spectrum of sensitivity to ALK mutations, complicating the optimal treatment strategy for the resistant population. Brigatinib (AP26113) is a novel highly selective and potent inhibitor of ALK and ROS1 with a high degree of selectivity. In vitro, brigatinib not only inhibited ALK with 12-fold higher potency compared to crizotinib, but also inhibited $I G F-1 R, F L T 3$ and EGFR mutants, with some activity against the $E G F R T 790 \mathrm{M}$ resistance mutation. In xenograft models, brigatinib overcomes resistance to ALK inhibitors, including the $A L K$ G1202R mutation, which is resistant to first- and secondgeneration inhibitors. The efficacy of brigatinib in crizotinib-resistant, $A L K$-positive patients has been demonstrated in two early studies, which led to its approval in this setting, and it is currently being investigated as the first-line therapy versus crizotinib in tyrosine kinase inhibitor-naïve patients. Brigatinib demonstrates not only promising whole-body activity, but also an impressive improvement of intracranial outcomes in terms of both objective response rate and progressionfree survival in the crizotinib-resistant population, with optimal efficacy at $180 \mathrm{mg}$ (following a $90 \mathrm{mg}$ run-in for 7 days) and good tolerance. These data confirm brigatinib as an excellent therapeutic strategy after crizotinib failure, particularly in the setting of central nervous system involvement. In this review, we summarize the two main clinical studies reported to date with brigatinib in $A L K$-positive advanced NSCLC patients, in particular, in the crizotinib-resistant population. We also address the mechanism of action for development of resistance and the challenging issues of optimal implementation for sequences of administration for ALK inhibitors. Keywords: NSCLC, ALK, crizotinib resistant, brigatinib
\end{abstract}

\section{Introduction}

ALK rearrangements are present in $\sim 5 \%$ of non-small cell lung cancer (NSCLC) patients, defining a specific molecular subgroup population. ${ }^{1}$ Over the last decade, the development of new and highly potent targeted therapies has enlarged the therapeutic strategy for advanced ALK-positive patients, achieving impressive improvements in survival.

Crizotinib was the first ALK inhibitor to be approved for the treatment of advanced NSCLC patients harboring an ALK rearrangement, first by the US Food and Drug Administration agency in August 2011 and subsequently by the European Medicines Agency in November 2012. In tyrosine kinase inhibitor (TKI)-naïve patients, crizotinib 
improves outcomes over platinum-based chemotherapy, the front-line standard of care until 2017, giving an objective response rate (ORR) of $74 \%$ and a median progression-free survival (PFS) of 10.9 months. $^{2}$

In 2017, Peters et al reported the results of the Phase III ALEX trial in which alectinib, a second-generation ALK inhibitor, was compared to crizotinib in the front-line setting. This study demonstrated an ORR of $83 \%$ (versus $76 \%$ with crizotinib), including central nervous system (CNS) activity, and a remarkable survival benefit with a median PFS of 25.7 months (versus 10.4 with crizotinib), resulting in alectinib taking over as the new standard of care in the first-line setting in $A L K$-positive patients. ${ }^{3}$ Ceritinib is another secondgeneration ALK inhibitor approved for first-line treatment of ALK-positive patients, due to the results of the Phase III ASCEND-4 study, which demonstrated a survival improvement for ceritinib over platinum-based chemotherapy, with a median PFS of 16.6 versus 8.1 months. $^{4}$

Despite these advances, most patients progress on ALK inhibitors within 2 years, with the brain being the most frequent site of relapse. ${ }^{5}$ ALK mutations, present in $\sim 30 \%$ of patients treated with ALK inhibitors, are the main known mechanism of resistance. ${ }^{6}$ Classically, second-generation ALK inhibitors such as alectinib or ceritinib have been the standard of care in the crizotinib-resistant population; ${ }^{7,8}$ however, each ALK inhibitor has a different spectrum of sensitivity to $A L K$ mutations, complicating the optimal treatment strategy for the resistant population.

The next-generation ALK inhibitors, such as brigatinib or lorlatinib, have a wider coverage of ALK resistance mutations, and sequential therapy with these ALK inhibitors is the preferred treatment approach in crizotinib-resistant and/or the second-generation-resistant populations, showing impressive responses and survival in pretreated crizotinib-resistant patients. Second- and third-generation ALK inhibitors have been evaluated versus crizotinib in the front-line setting to establish the optimal sequence of ALK inhibitors.

In this review, we summarize the two main clinical studies reported to date with brigatinib in $A L K$-positive advanced NSCLC patients and, in particular, in the crizotinib-resistant population. We also address the mechanism of action for development of resistance and the challenging issues of optimal implementation for sequences of administration for ALK inhibitors.

\section{Mechanism of action}

Brigatinib (AP26113; ARIAD Pharmaceuticals, Cambridge, MA, USA) is a 2,4-diarylaminopyrimidine, a novel highly-selective and potent inhibitor of ALK ( $\mathrm{IC}_{50}$, $14 \mathrm{nmol} / \mathrm{L})$ and $\mathrm{ROS} 1\left(\mathrm{IC}_{50}, 18 \mathrm{nmol} / \mathrm{L}\right)$, with a high degree of selectivity when compared to a panel of more than 250 kinases. ${ }^{9}$ In vitro, brigatinib inhibited $A L K$ with a 12 -fold higher potency compared to crizotinib, while it inhibited FLT3 and IGF-1R with an 11-fold lower potency than $A L K$ $\left(\mathrm{IC}_{50}, 148-158 \mathrm{nmol} / \mathrm{L}\right)$ and $F L T 3$ and EGFR mutants with a 15-fold to 35-fold lower potency, respectively $\left(\mathrm{IC}_{50}, 211-489\right.$ $\mathrm{nmol} / \mathrm{L})$, with some activity against the EGFRT790M resistance mutation $\left(\mathrm{IC}_{50}, 489 \mathrm{nmol} / \mathrm{L}\right)$. In animal models, brigatinib has demonstrated overcoming resistance mechanism to ALK inhibitors, including the $A L K$ G1202R mutation, which is resistant to first and second generation. ${ }^{10}$ Structurally, brigatinib has the unique feature of containing a phosphine oxide, a novel and little known hydrogen-bond acceptor that confers its highly selective potency and favorable pharmacokinetic and pharmacodynamic characteristics.

\section{Clinical activity}

Brigatinib was first assessed in a single-arm, open-label, Phase 1/2 trial designed to establish a recommended Phase II dose, characterize safety and perform a preliminary evaluation of efficacy. A total of 137 patients with advanced tumors were included in the USA and Spain, including 79 TKI-naïve and crizotinib-resistant $A L K$-positive NSCLC patients. ${ }^{11-13}$

In the initial dose-escalation part, daily doses of oral brigatinib from 30 to $300 \mathrm{mg}$ were evaluated. Two patients had dose-limiting toxicity, one grade 3 ALT elevation (at $240 \mathrm{mg}$ ) and the other one grade 4 dyspnea (at $300 \mathrm{mg}$ ), and the recommended Phase II dose was established as $180 \mathrm{mg}$ daily. In the Phase II expansion part, three oral daily doses were assessed, 90, 180 and $180 \mathrm{mg}$, after a 7-day run-in at 90 $\mathrm{mg}$. Five cohorts of patients were included - ALK inhibitornaive NSCLC (cohort 1), crizotinib-resistant $A L K$-positive NSCLC (cohort 2), EGFRT790M-positive NSCLC resistant to one prior EGFR TKI (cohort 3), other non-NSCLC tumors with molecular alterations in brigatinib targets (cohort 4) and crizotinib-naive or crizotinib-resistant $A L K$-positive NSCLC with active, measurable CNS involvement (cohort 5). The Phase II primary endpoint was the assessment of ORR by Response Evaluation Criteria in Solid Tumors v1.1 (Table 1).

An efficacy analysis was performed in the $79 \mathrm{ALK}$ positive (58\%) advanced NSCLC patients, 78 of whom were evaluable. The ORR was $62 \%(44 / 51)$ in crizotinib-resistant patients and $100 \%(8 / 8)$ in crizotinib-naïve patients. All four patients in cohort 1 had a response, giving a $100 \%$ ORR in this group (95\% CI 40-100), and 31/42 (74\% [95\% CI 58-86]) in cohort 2 , none $(0 / 1)$ in cohort $3,3 / 18(17 \%$ 


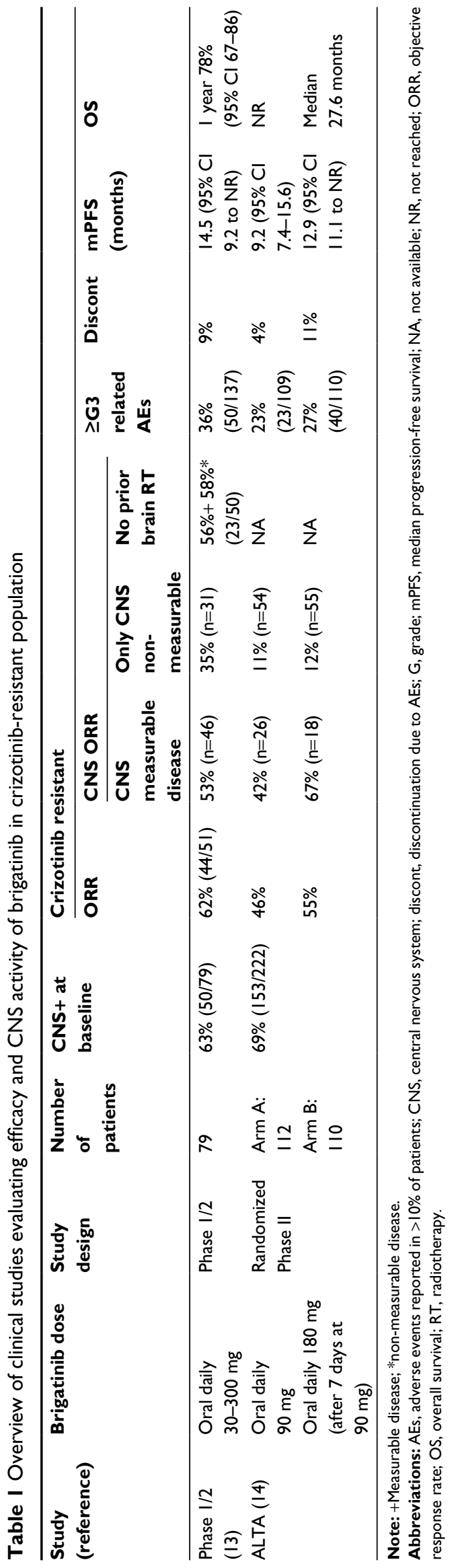

[95\% CI 4-41]) in cohort 4 and 5/6 (83\% [95\% CI 36-100]) in cohort 5 showed response (Table 2).

Median duration of response was 11.2 months (95\% CI 7.6-29.7) in the 51 crizotinib-resistant patients and was not reached (NR) in the crizotinib-naive patients $(95 \%$ CI 5.6 to NR). Median PFS (Phase II secondary outcome) was NR in the crizotinib-naïve cohort (95\% CI 7.4 months to NR), 14.5 months ( $95 \%$ CI 9.2 to NR) in the crizotinib-resistant cohort and 1.8 months (95\% CI 1.7-3.7) in the brigatinib-targeted alterations cohort; only one EGFRT790M-positive patient had an event (progression) at 7.4 months.

The second study evaluating brigatinib in crizotinibresistant, $A L K$-positive NSCLC patients was the ALTA trial, a randomized, multicenter, Phase II trial assessing efficacy and safety. ${ }^{14}$ Two brigatinib regimens, initially assessed in the Phase II part of the initial Phase 1/2 trial, were evaluated. Patients were randomized (1:1) to receive oral brigatinib 90 $\mathrm{mg}$ once daily (arm A) or $180 \mathrm{mg}$ once daily with a 7-day run-in at $90 \mathrm{mg}$ (arm B), and were stratified by brain metastasis and prior response to crizotinib. The primary endpoint was investigator-assessed confirmed ORR. A total of 222 patients were enrolled (arm A: n=112, 109 treated; arm B: $\mathrm{n}=110,110$ treated), 154 (69\%) of whom had baseline brain metastases. Results were reported after a median follow-up of 8 months, showing impressive outcomes, with an ORR of $45 \%(97.5 \%$ CI $34 \%-56 \%)$ and $54 \%(97.5 \%$ CI $43 \%-65 \%)$ in arms A and B, respectively, while median PFS was 9.2 months (95\% CI 7.4-15.6) and 12.9 months (95\% CI 11.1 to NR) in arms A and B, respectively, supporting better efficacy with the $180 \mathrm{mg}$ dose.

Based on the findings from these two early studies, on April 28, 2017, the US Food and Drug Administration granted accelerated approval to brigatinib for the treatment of metastatic crizotinib-resistant, $A L K$-positive NSCLC patients. An update of the ALTA trial was presented at the 2017 International Association for the Study of Lung Cancer World Conference on Lung Cancer, supporting these results, notably for the $180 \mathrm{mg}$ daily dose. With a median follow-up of 16.8 and 18.6 months in arms A and B respectively, the ORR was $46 \%$ (arm A) and 55\% (arm B) by investigator assessment, with a median duration of response of 12 and 13.8 months, respectively. Median PFS was 9.2 months in arm A and 15.6 months in arm B. Median overall survival (OS) was NR in arm A and was 27.6 months in arm B.

Based on the promising results in crizotinib-naïve patients from the Phase $1 / 2$ study, brigatinib is now being assessed in the front-line setting in the multicenter, randomized, Phase III ALTA 1L trial (NCT02737501). Approximately 
270 advanced TKI-naïve, $A L K$-positive NSCLC patients with no more than one prior line of systemic treatment will be randomized (1:1) to receive brigatinib (1 week at $90 \mathrm{mg}$ daily followed by $180 \mathrm{mg}$ daily) or crizotinib ( $250 \mathrm{mg}$ twice a day). Patients with asymptomatic or controlled brain and leptomeningeal metastasis are eligible. The primary endpoint is PFS as per Response Evaluation Criteria in Solid Tumors v1.1 assessed by a blinded independent review committee (BIRC); the secondary endpoints include ORR, duration of response, OS, safety/tolerability, patient-reported outcomes (PROs) and intracranial outcomes. Recruitment started in April 2016 and is ongoing.

In summary, the efficacy of brigatinib in crizotinibresistant, $A L K$-positive patients has been demonstrated in two early studies leading to its approval in this setting, and it is currently being investigated as a first-line therapy versus crizotinib in TKI-naïve patients to establish the best sequence of ALK inhibitors in this population.

\section{CNS activity}

Brain is the primary site of failure with ALK inhibitors in $A L K$-positive patients, occurring in $20 \%$ of patients with no prior CNS involvement and in up to $70 \%$ of patients with CNS involvement at diagnosis. ${ }^{3,5,15}$ Consequently, CNS outcomes are a primary consideration in terms of the global efficacy of any ALK inhibitor.

In general, the second-generation ALK inhibitors show better diffusion across the brain-blood barrier, improving the CNS outcomes compared to crizotinib. ${ }^{3}$ It is hoped that the next-generation ALK inhibitors including brigatinib may further enhance this property.

CNS activity of brigatinib was evaluated in the Phase $1 / 2$ trial in the 50 patients $(63 \%)$ with CNS involvement. Fortysix $(92 \%)$ of them had measurable CNS disease (with at least one follow-up scan), assessable for intracranial response, with a CNS ORR of 53\%. Among the 31 patients with only nonmeasurable CNS disease, the CNS ORR was $35 \%$ (Table 1 ).

For all 19 evaluable patients with complete response (for all measurable and non-measurable disease), the median duration of CNS response was 18.9 months (95\% CI 5.5 to $\mathrm{NR}$ ); however, with only seven events at the cut-off, more mature data are needed to more accurately evaluate this activity. Median CNS PFS in the 46 evaluable patients was 15.6 months ( $95 \%$ CI 13.0 to NR). The CNS ORR in the crizotinib-naïve patients was $50 \%$ (3/6) and no events were reported in the CNS+ crizotinib-naïve cohort (Table 1).

Twenty-three patients (46\%) with CNS involvement had not received previous brain radiotherapy, of whom 21 were 
assessable. Of them, $56 \%$ with measurable CNS disease $(n=9)$ and $58 \%$ with non-measurable CNS disease $(n=12)$ achieved a confirmed CNS ORR. Median CNS PFS was 22.3 months (95\% CI 8.0-22.3).

Of the 25 patients who had been previously treated with brain radiotherapy, 20 patients had received this therapy more than 4 months earlier. The CNS ORRs were $53 \%(n=8 / 15)$ and $35 \%(n=11 / 31)$ in CNS measurable and non-measurable disease, respectively.

In the Phase II ALTA trial, 153 patients (69\%) of the 222 enrolled had baseline brain metastases. A total of 44 (29\%) patients were assessable for intracranial response $(n=26$ $\operatorname{arm} \mathrm{A}, \mathrm{n}=18$ arm B), giving a CNS ORR of $42 \%$ in $\operatorname{arm~A}$ and $67 \%$ in arm $\mathrm{B}$. The median duration of CNS activity in patients with CNS response was NR (95\% CI 3.7 to NR in $\operatorname{arm~A;~95\% ~CI~} 5.6$ to NR in arm B). The median CNS PFS was 15.8 months $(95 \%$ CI 7.3-15.7) and 12.8 months $(95 \%$ CI 11.0 to NR) in arms A and B, respectively.

In the 2017 update of the ALTA trial reported at the 2017 IASLC World Conference on Lung Cancer, the BIRCassessed CNS ORRs were 50\% and 67\% in arms A and B, respectively. The median duration of CNS response was NR in $\operatorname{arm} \mathrm{A}$ and 16.6 months in $\operatorname{arm} \mathrm{B}$. Considering all patients with CNS involvement at baseline, the median CNS PFS as assessed by the BIRC was 12.8 months in arm A and 18.4 months in arm B.

Thus, brigatinib demonstrates not only promising whole-body activity, but also an impressive improvement of intracranial outcomes in terms of both ORR and PFS in the crizotinib-resistant population, with optimal efficacy at $180 \mathrm{mg}$ (following a $90 \mathrm{mg}$ run-in for 7 days). These data confirm brigatinib as an excellent therapeutic strategy after crizotinib failure, particularly in the setting of CNS involvement.

\section{Safety profile and tolerance}

$A L K$-positive patients are typically exposed to ALK inhibitors not only for long periods, but also sequentially, making safety and tolerability critical endpoints for therapeutic management.

The safety of brigatinib was first assessed in the Phase $1 / 2$ trial in patients with advanced tumors. ${ }^{11-13}$ In the dose escalation part, two dose-limiting toxicities were observed, grade 3 ALT elevation (at $240 \mathrm{mg}$ ) and grade 4 dyspnea (at $300 \mathrm{mg}$ ), and $180 \mathrm{mg}$ was selected as the Phase II recommended dose. Safety was assessed in all 137 treated patients (from both parts of the study). The most frequent adverse events were nausea (52\%), fatigue (42\%) and diarrhea (40\%). Treatment-related adverse events of grade 3 or more included elevated lipase $(9 \%)$, pneumonia $(7 \%)$, dyspnea $(6 \%)$, and hypoxia (5\%). Sixteen (12\%) patients died during treatment or within 31 days of the last dose of brigatinib, which was due to progression in 8 of 16 cases (Table 3 ).

The authors reported a subset of pulmonary events occurred within 7 days of treatment initiation (or after reinitiation following a dose interruption) at the dose of 180 mg once daily, usually as an early event (within 24-48 hours), with a median time to onset of 2 days (interquartile range 2-2). These events included dyspnea, hypoxia, cough, pneumonia and pneumonitis, often with chest imaging findings

Table 3 Safety profile of brigatinib from the Phase I/2 trial and the Phase II ALTA trial

\begin{tabular}{|c|c|c|c|c|c|c|c|}
\hline $\begin{array}{l}\text { Study } \\
\text { (reference) }\end{array}$ & Dose & $\begin{array}{l}\text { Number of } \\
\text { patients }\end{array}$ & $\begin{array}{l}\text { All grade } \\
\text { TRAEs }\end{array}$ & $\geq$ Grade 3 TRAEs & $\begin{array}{l}\text { All grade } \\
\text { pulmonary } \\
\text { events }\end{array}$ & $\begin{array}{l}\text { Dose reduction } \\
\text { (\% patients) }\end{array}$ & $\begin{array}{l}\text { Discontinuation } \\
\text { (\% patients) }\end{array}$ \\
\hline Phase I/2 (I3) & $\begin{array}{l}\text { Oral daily } \\
30-300 \mathrm{mg}\end{array}$ & 137 & $\begin{array}{l}\text { Nausea }(52 \%) \\
\text { Diarrhea }(40 \%) \\
\text { Fatigue }(42 \%)\end{array}$ & $\begin{array}{l}36 \% \\
\text { Elevated lipase (9\%) } \\
\text { Hypertension }(5 \%) \\
\text { Dyspnea }(6 \%)\end{array}$ & $\begin{array}{l}2 \% \text { at } 90 \mathrm{mg} \\
14 \% \text { at } 180 \mathrm{mg} \\
50 \% \text { at } 300 \mathrm{mg}\end{array}$ & 15 & 9 \\
\hline ALTA trial (I4) & $\begin{array}{l}\text { Oral daily } \\
90 \mathrm{mg}\end{array}$ & Arm A: 109 & $\begin{array}{l}\text { Nausea }(33 \%) \\
\text { Diarrhea }(19 \%) \\
\text { Headache }(28 \%) \\
\text { Cough }(18 \%)\end{array}$ & $\begin{array}{l}23 \% \\
\text { Elevated CPK (3\%) } \\
\text { Hypertension (4\%) } \\
\text { Elevated lipase (4\%) } \\
\text { Pneumonitis (2\%) }\end{array}$ & $\begin{array}{l}\text { All grades: } 6 \% \\
\geq \text { Grade } 3: 3 \%\end{array}$ & 9 & 4 \\
\hline & $\begin{array}{l}\text { Oral daily } \\
180 \mathrm{mg} \text { (after } \\
7 \text { days at } \\
90 \mathrm{mg} \text { ) }\end{array}$ & Arm B: IIO & $\begin{array}{l}\text { Nausea }(40 \%) \\
\text { Diarrhea (38\%) } \\
\text { Headache (27\%) } \\
\text { Cough (34\%) }\end{array}$ & $\begin{array}{l}27 \% \\
\text { Elevated CPK (II\%) } \\
\text { Hypertension (4\%) } \\
\text { Elevated lipase (4\%) } \\
\text { Pneumonitis (4\%) }\end{array}$ & & 30 & 11 \\
\hline
\end{tabular}

Abbreviations: CPK, creatine phosphokinase; G, grade; TRAEs, treatment-related adverse events. 
of linear or ground-glass pulmonary opacities, without any apparent alternative cause. Incidence was dose dependent, increasing from $2 \%$ to $14 \%$ at 90 and $180 \mathrm{mg}$ once daily and to $50 \%$ at $300 \mathrm{mg}$ once daily. Two of 11 patients (18\%) rechallenged with brigatinib had recurrence of pulmonary event. No definitive discontinuations due to this event occurred.

In the ALTA trial, the profile of common treatmentrelated adverse events was similar to that of the Phase $1 / 2$ study, with nausea ( $\operatorname{arm~A/B,~33\% /40\% ),~diarrhea~(~} \operatorname{arm~A/B,~}$ $19 \% / 38 \%$ ), headache (arm A/B, 28\%/27\%) and cough (arm $\mathrm{A} / \mathrm{B}, 18 \% / 34 \%$ ), which were mainly grade 1 or 2 . Early pulmonary events (within the first 48 hours) were also seen in 14 of the 219 patients (all grades, 6\%, including $\geq$ grade 3 in $3 \%$ ), although in arm B, no cases were reported after the initial run-in dose was increased to $180 \mathrm{mg}$. Of these 14 patients, 7 (50\%) were retreated, none of whom experienced repetition of the event.

In the ALTA trial update, the most common grade 3 or higher treatment-related adverse events in arms A and B included increased blood creatine phosphokinase $(3 \%$ and $11 \%$ ), hypertension ( $4 \%$ and $4 \%$ ), increased lipase (4\% and $4 \%$ ), rash (1\% and $4 \%$ ) and pneumonitis (2\% and $4 \%$ ). Dose reduction due to adverse events was implemented in $9 \%$ and $30 \%$ of patients in arms $\mathrm{A}$ and $\mathrm{B}$, respectively, and treatment discontinuation due to adverse events occurred in $4 \%$ and $11 \%$ in arms $\mathrm{A}$ and $\mathrm{B}$, respectively.

The tolerability profile was also assessed from the patients' perspective in the ALTA trial, according to PROs, as reported by Langer et al at the 2017 the American Society of Medical Oncology meeting. ${ }^{16}$ The European Organisation for Research and Treatment of Cancer Quality of life questionnaire-C30 (QLQ-C30) questionnaires were completed at baseline and on the first day of each cycle, and 208 (94\%) of the 222 randomized patients were evaluated. No statistically significant differences were found in Global Health Status/ Quality of Life score between arms, adjusted for baseline score, performance status (PS), and presence of liver/bone metastases. At Cycle 5, 80\% of all patients reported an improvement or no change in Global Health Status/Quality of Life scores, with $50 \%$ reporting clinically meaningful improvement, and around $30 \%$ had clinically meaningful reduction in symptoms (i.e., $80 \%$ and $90 \%$ reported reduction or no change in pain and dyspnea, respectively). Less than $15 \%$ and $5 \%$ of patients reported clinically meaningful worsening of nausea/vomiting and diarrhea, respectively.

The relatively well-tolerated profile together with the above-described efficacy outcomes in the crizotinib-resistant population support a role for brigatinib as an optimal therapy in $A L K$-positive NSCLC patients.

\section{Overcoming ALK resistance mechanisms}

The development of resistance to ALK inhibitors remains a major challenge in the therapeutic decision-making process for ALK-rearranged NSCLC patients. Secondary ALK resistance mutations are the main known mechanism of resistance to ALK inhibitors, present in $\sim 30 \%$ of advanced NSCLC patients. ${ }^{6}$ Most of these acquired $A L K$ mutations generate conformational changes in the ALK protein, interfering with the binding of the inhibitors.

The development of ALK resistance mutations is more frequent in patients treated with second- or next-generation ALK inhibitors. Gainor et al reported a $20 \%$ rate of ALK mutations at progression under crizotinib $(n=50)$ versus $53 \%-54 \%$ at progression under second-generation ALK inhibitors $(n=41)$ and $71 \%$ under brigatinib $(n=7){ }^{6}$ The ALKL1196M gatekeeper mutation is the most frequent mutation after progression following crizotinib exposure, and the ALK G1202R mutation is the most common mutation under second-generation inhibitors.

Additionally, the type of ALK inhibitor to which the patient has been exposed impacts the spectrum of $A L K$ resistance mutations found, with broad analyses of mutational profiles in relation to ALK inhibitors showing that each inhibitor is associated with a distinct sensitivity profile to all ALK resistance mutations, with the optimal profile found with next-generation ALK inhibitors such as brigatinib. In vitro, brigatinib has demonstrated remarkable inhibition of cell growth in patient-derived cell lines harboring $A L K \mathrm{C} 1156 \mathrm{Y}, A L K I 1171 \mathrm{~N}, A L K I 1171 \mathrm{~S}, A L K I 1174 \mathrm{C}$, ALKL1196M, ALKL1198F, ALKD1203N, and ALKE1210K mutations $\left(\mathrm{IC}_{50}<50 \mathrm{nM}\right.$ ), whereas moderate inhibition $\left(\mathrm{IC}_{50}\right.$ $>50 \mathrm{nM}<200 \mathrm{nM}$ ) was seen in cell lines harboring $A L K$ G1202R and $A L K$ G1202 deletions, or complex patterns of $A L K$ mutations such as $A L K \mathrm{D} 1203 \mathrm{~N}+A L K \mathrm{~F} 1174 \mathrm{C}$ and $A L K \mathrm{D} 1203 \mathrm{~N}+A L K \mathrm{E} 1210 \mathrm{~K} .{ }^{6}$ Although the identification of ALK resistance mutations is a strategic weapon when selecting subsequent lines of therapy, particularly interesting for the next-generation ALK inhibitors, the clinical impact of these findings remain unknown.

In addition, it is important to note that biopsy collection upon progression is not an option for all $A L K$-positive patients given that the first site of failure is commonly the CNS. Taking this into consideration, the development of new non-invasive alternative tools, such as the liquid biopsy in plasma, has been explored in this setting to assess resistance mutations. Bazhenova et al recently presented interesting data on the role of the liquid biopsy in detecting $A L K$ fusions and mutations at baseline in plasma from patients in the Phase 1/2 ALTA trial. ${ }^{17}$ 
Out of 291 patients enrolled, 67 patients (23\%) had baseline plasma samples or analysis (Resolution Bioscience ctDx Lung Panel v3.0). ALK fusions were detected in 45\% (30/67), 33\% of whom (10/30) had secondary $A L K$ mutations. Complex patterns of mutations were observed, including between one and six $A L K$ resistance mutations per patient, and secondary driver mutations such as BRAFV600E or KRASG12D were identified in combination with $A L K$ resistance in one patient.

Gettinger et al also reported the efficacy of brigatinib according to the $A L K$ resistance mutations detected in plasma at baseline or at progression under brigatinib from patients in the Phase $1 / 2$ ALTA trial. ${ }^{12}$ Thirty of 301 patients (10\%) had evaluable samples (FoundationOne next-generation sequencing platform). Nine patients (30\%) presented $A L K$ resistance mutations (three patients had $A L K \mathrm{~F} 1174 \mathrm{~L}$, and ALKL1196M, ALKS1206F, ALKG1269A, ALK G1202R, $A L K L 1196 \mathrm{M}$ and $A L K \mathrm{~F} 1245 \mathrm{~V}$ were reported in one patient each). Taken together, these preliminary data support the feasibility of liquid biopsies for detecting $A L K$ resistance mutations, which can be used when selecting subsequent anti-ALK therapy. However, large-scale studies are needed to optimize their application in the clinic.

In terms of ALK-independent mechanisms, a bypass mechanism via activation of EGFR-signaling pathways ${ }^{18}$ is reported in around $30 \%$ of cases of resistance; however, to date, anti-EGFR therapies have not been explored as a therapeutic strategy. Taking this into consideration, a double inhibitory approach using brigatinib as an anti-ALK and an anti-EGFR is an excellent candidate combination meriting assessment in a resistant population in which EGFR bypass signaling appears the predominant resistance mechanism. Brigatinib was recently proposed in combination with an anti-EGFR antibody as a means of overcoming resistance to osimertinib, a third-generation EGFR TKI, due to its structural characteristic of being able to fit into the ATPbinding pocket of the triple-mutant C797S/T790M/activating EGFR mutation. ${ }^{19}$ Further studies are warranted in both $A L K$-rearranged and $E G F R$ mutant populations.

\section{Future perspectives}

The efficacy of brigatinib in crizotinib-resistant, $A L K$-positive patients has been established in two early development studies, and is currently being investigated in TKI-naïve patients in the Phase III ALTA 1L trial versus crizotinib to define the optimal sequence of ALK inhibitors in this population. The currently used sequence of therapy with a first-generation ALK inhibitor followed by second- or next-generation ALK inhibitor could be modified if brigatinib improves the benefit compared to crizotinib. A direct comparison of brigatinib versus a second-generation ALK inhibitor (alectinib or ceritinib) is not currently planned, although such a study would be valuable given that alectinib and ceritinib will become the standard of care in the front-line setting, with $A L K$ resistance mutations found more frequently at progression compared to crizotinib. In this scenario, the next-generation ALK inhibitors such as brigatinib will have a predominant role, considering that they can address ALK resistance mutations.

However, today, the optimal sequence of ALK inhibitors remains to be defined with respect to second-generation ALK inhibitors and next-generation ALK inhibitors such as brigatinib that may replace the prior generation ALK inhibitors.

For now, the primary unanswered question is to define the optimal upfront inhibitor, with the secondary important issue to address being the best sequence of ALK inhibitors, maintaining the option of crizotinib in the front-line setting for certain patients. At ESMO 2017, Mok et $\mathrm{al}^{20}$ reported an update of OS from the Phase III PROFILE 1014 trial comparing crizotinib versus chemotherapy, with a median follow-up duration for OS of 46 months in both arms. Median OS was NR with front-line crizotinib (95\% CI 45.8 to NR) versus 47.5 months (95\% CI 32.2 to NR) with chemotherapy. Although these findings were not statistically significant, they showed impressive survival data for $A L K$-positive patients, with first-line crizotinib followed by second or third-generation ALK inhibitors, emphasizing the importance of the proper sequence of the available ALK inhibitors. The mature OS data of the ALEX and ASCEND 4 should help establish whether a second-generation ALK inhibitor upfront is a more successful approach.

Assessment of the molecular mechanisms of resistance could also have an impact in the decision-making process, on which the sequence of therapy with first- or secondgeneration followed by next-generation inhibitors according to $A L K$ resistance mutations is also an appropriate strategy.

\section{Conclusion}

Brigatinib has shown efficacy including impressive intracranial activity and a good safety profile in a crizotinibresistant, $A L K$-positive population. More data are needed to clearly establish the optimal place for brigatinib in sequential therapy, as first-line therapy according to the ALTA 1L trial or after second-generation ALK inhibitors. The selection of an ALK inhibitor by $A L K$ resistance mutations could tip the balance in favor of brigatinib, considering its broad coverage of resistance mutations, which is of particular value in the context of post-second-generation ALK inhibitors. 


\section{Acknowledgment}

The authors thank Sarah McKenzie, PhD for English language editing.

\section{Disclosure}

The authors report no conflicts of interest in this work.

\section{References}

1. Shaw AT, Yeap BY, Mino-Kenudson M, et al. Clinical features and outcome of patients with non-small-cell lung cancer who harbor EML4ALK. J Clin Oncol. 2009;27(26):4247-4253.

2. Solomon BJ, Mok T, Kim DW, et al; PROFILE 1014 Investigators. First-line crizotinib versus chemotherapy in ALK-positive lung cancer. N Engl J Med. 2014;371(23):2167-2177.

3. Peters S, Camidge DR, Shaw AT et al; ALEX Trial Investigators. Alectinib versus crizotinib in untreated ALK-positive non-small-cell lung cancer. $N$ Engl J Med. 2017;377(9):829-838.

4. Soria JC, Tan DSW, Chiari R, et al. First-line ceritinib versus platinumbased chemotherapy in advanced ALK-rearranged non-small-cell lung cancer (ASCEND-4): a randomised, open-label, phase 3 study. Lancet. 2017;389(10072):917-929.

5. Costa DB, Shaw AT, Ou SH, et al. Clinical experience with crizotinib in patients with advanced ALK-rearranged non-small-cell lung cancer and brain metastases. J Clin Oncol. 2015;33(17):1881-1888.

6. Gainor JF, Dardaei L, Yoda S, et al. Molecular mechanisms of resistance to first- and second-generation ALK inhibitors in ALK-rearranged lung cancer. Cancer Discov. 2016;6(10):1118-1133.

7. Shaw AT, Gandhi L, Gadgeel S, et al; study investigators. Alectinib in ALK-positive, crizotinib-resistant, non-small-cell lung cancer: a singlegroup, multicentre, phase 2 trial. Lancet Oncol. 2016;17(2):234-242.

8. Crinò L, Ahn MJ, De Marinis F, et al. Multicenter Phase II study of whole-body and intracranial activity with ceritinib in patients with ALK-rearranged non-small-cell lung cancer previously treated with chemotherapy and crizotinib: results from ASCEND-2. J Clin Oncol. 2016;34(24):2866-2873.

9. Huang WS, Liu S, Zou D, et al. Discovery of brigatinib (AP26113), a phosphine oxide-containing, potent, orally active inhibitor of anaplastic lymphoma kinase. J Med Chem. 2016;59(10):4948-4964.

10. Zhang S, Anjum R, Squillace R, et al. The potent ALK inhibitor brigatinib (AP26113) overcomes mechanisms of resistance to first- and second-generation ALK inhibitors in preclinical models. Clin Cancer Res. 2016;22(22):5527-5538.
11. Camidge DR, Bazhenova L, Salgia R, et al. Safety and efficacy of brigatinib (AP26113) in advanced malignancies, including ALK+ non-small cell lung cancer (NSCLC). J Clin Oncol. 2015;33(suppl; abstr 8062).

12. Rosell R, Gettinger SN, Bazhenova LA, et al. 1330: Brigatinib efficacy and safety in patients (Pts) with anaplastic lymphoma kinase (ALK)positive (ALK+) non-small cell lung cancer (NSCLC) in a phase 1/2 trial. J Thorac Oncol. 2016;11(4 Suppl):S114.

13. Gettinger SN, Bazhenova LA, Langer CJ, et al. Activity and safety of brigatinib in ALK-rearranged non-small-cell lung cancer and other malignancies: a single-arm, open-label, phase 1/2 trial. Lancet Oncol. 201617(12):1683-1696

14. Kim DW, Tiseo M, Ahn MJ, et al. Brigatinib in patients with crizotinibrefractory anaplastic lymphoma kinase-positive non-small-cell lung cancer: a randomized, multicenter Phase II trial. J Clin Oncol. 2017;35(22):2490-2498.

15. Solomon BJ, Cappuzzo F, Felip E, et al. Intracranial efficacy of crizotinib versus chemotherapy in patients with advanced ALK-positive non-small-cell lung cancer: results from PROFILE 1014. J Clin Oncol. 2016;34(24):2858-2865.

16. Langer CJ, Huang H, Huang J, et al. Patient-reported outcomes and quality of life in ALTA: The randomized phase 2 study of brigatinib (BRG) in advanced ALK+ non-small cell lung cancer (NSCLC). [Internet]. [cited August 20, 2017]. Available from: http://meetinglibrary.asco. org/record/145768/abstract. Accessed August 20, 2017.

17. Bazhenova L, Hodgson JG, Langer CJ, et al. Activity of brigatinib (BRG) in crizotinib (CRZ)-resistant ALK+ NSCLC patients (pts) according to ALK plasma mutation status. [Internet]. [cited August 13, 2017]. Available from: http://meetinglibrary.asco.org/record/145774/ abstract. Accessed August 13, 2017.

18. Camidge DR, Pao W, Sequist LV. Acquired resistance to TKIs in solid tumours: learning from lung cancer. Nat Rev Clin Oncol. 2014;11(8): 473-481.

19. Uchibori $\mathrm{K}$, Inase $\mathrm{N}$, Araki $\mathrm{M}$, et al. Brigatinib combined with antiEGFR antibody overcomes osimertinib resistance in EGFR-mutated non-small-cell lung cancer. Nat Commun. 2017;8:14768.

20. Mok TS, Kim D, Wu Y, Nakagawa K, Mekhail T, Felip E, et al. Overall Survival (OS) for First-Line Crizotinib Versus Chemotherapy in ALK+ Lung Cancer: Updated Results from PROFILE 1014. Annals of Oncology (2017) 28 (suppl_5): v605-v649. 10.1093/annonc/mdx440.
Cancer Management and Research

\section{Publish your work in this journal}

Cancer Management and Research is an international, peer-reviewed open access journal focusing on cancer research and the optimal use of preventative and integrated treatment interventions to achieve improved outcomes, enhanced survival and quality of life for the cancer patient. The manuscript management system is completely online and includes 